\title{
A MICROBIAL PROFILE OF PATIENTS WITH CHOLECYSTITIS AND/OR CHOLELITHIASIS UNDERGOING CHOLECYSTECTOMY ALONG WITH THEIR ANTIBIOGRAM
}

\author{
Shailendra Garg1, Mahesh Kumar², Geeta Parihar ${ }^{3}$ \\ ${ }_{1}^{1}$ Assistant Professor, Department of Microbiology, JLN Medical College, Ajmer. \\ 2Senior Demonstrator, Department of Microbiology, RNT Medical College, Udaipur. \\ ${ }^{3}$ Senior Professor and HOD, Department of Microbiology, JLN Medical College, Ajmer.
}

\begin{tabular}{l}
\hline ABSTRACT \\
\hline BACKGROUND \\
Biliary tract disease is common cause of bacteraemia, associated with high morbidity and mortality. Most common infecting \\
organisms are from Enterobacteriaceae family. Complications of bacteraemia are acute renal failure \& septic shock.
\end{tabular}

\section{MATERIALS AND METHODS}

The study was conducted on 50 cases of cholelithiasis (who were admitted and treated in different units of General Surgery Department) and had undergone open or laparoscopic cholecystectomy. The samples collected were blood or bile, and then Gallstone Culture, Antibiogram Testing, Biochemical test (indole, methyl red, etc.) were performed.

\section{RESULTS}

Gallstones disease was more common in females as compared to males (F:M:3.5: 1) and the maximum age incidence was in 41-50 years age group (38\%). Pain abdomen was the predominant symptom present in $88 \%$ of cases, flatulent dyspepsia in $44 \%$ cases and nausea/vomiting in 32\% cases, while tenderness in right hypochondrium was present in $44 \%$ of cases. Out of total 50 cases, 18 (36\%) showed positive bile cultures and incidence of positive cultures increased with advancing age with maximum being positive in 41-60 years age group. Gallstone culture was positive in 28 cases (56\%). Most common organism isolated from bile was E. coli (44\% of positive cases) followed by Klebsiella (22\%) and Pseudomonas (16\%).

\section{CONCLUSIONS}

Infection plays a key role in pathogenesis of chronic calculous cholecystitis and bile and gallstone culture is a good method to demonstrate the infective potential of bacteria colonising the gall bladder.

\section{KEYWORDS}

Biliary Tract Disease, Bacteraemia, Cholelithiasis, Open or laparoscopic Cholecystectomy, Gallstone Culture, Antibiogram Testing.

HOW TO CITE THIS ARTICLE: Garg S, Kumar M, Parihar G. A microbial profile of patients with cholecystitis and/or cholelithiasis undergoing cholecystectomy along with their antibiogram. J. Evolution Med. Dent. Sci. 2016;5(97):7134-7140, DOI: $10.14260 /$ Jemds/2016/1615

\section{BACKGROUND}

Gallbladder disease has been recognised for nearly 1500 years and remains a major world health problem.

It is one of the most common disorders affecting the gastrointestinal tract and is an important cause of morbidity. At least three hundred million people inhabiting our planet are suffering from cholelithiasis. The incidence being $11-36 \%$ of the population. ${ }^{1}$

Cholecystitis and cholelithiasis with its complications dominate the disease of the biliary tract. Gall bladder disease has a wide geographic variation, being common in the US where an estimated 15 million people have disease of the biliary tract and of these $1 / 5^{\text {th }}$ or 3 million undergo biliary tract operations every year.

This disease is rare in the first two decades. Incidence gradually increases after 21 years and reaches its peak in the fifth and sixth decades. ${ }^{2}$

Financial or Other, Competing Interest: None.

Submission 28-10-2016, Peer Review 20-11-2016,

Acceptance 27-11-2016, Published 05-12-2016.

Corresponding Author:

Dr. Shailendra Garg,

\#1 K, 14 Near Shopping Centre-1,

Shastrinagar, Ajmer.

E-mail:drshailygarg98@gmail.com

DOI: $10.14260 /$ jemds $/ 2016 / 1615$

Women are three times more likely to develop gallstone disease than men and first degree relatives of patients with cholelithiasis have a twofold greater prevalence of this disease. ${ }^{1}$

Gallstone disease is common and costly with over seven lakh cholecystectomies annually. In developed countries at least $10 \%$ of adults have cholesterol gallstones. Women have twice the risk and age further increases the prevalence in both sexes.

In India, gall bladder disease is much more common in North India than in South India. Similarly the incidence is higher in Eastern India than Western India. ${ }^{3}$

Different reasons for biliary tract infection have been presented, e.g. ascending infection due to reflex of duodenal contents, blood borne infection and infection spread through the portal venous channels. Ascending infection from the duodenum is thought to be the primary mechanism by which bacteria enter the bile. Different microbes in the bile may be the cause to post-cholecystectomy infections. Thus, understanding the most common organisms causing them and their antibacterial susceptibility pattern would be useful in prevention of these infections. 4

Biliary tract disease is a common cause of bacteraemia and is associated with high morbidity and mortality, particularly in older patients with comorbid disease or when there is a delay 
in diagnosis and treatment. The most common infecting organisms are Enterobacteriaceae ascending from the gastrointestinal tract.5,6,7

In patients with bacteraemia, complications such as acute renal failure and septic shock occur more commonly, so an improved understanding of the causative organisms, susceptibility profiles results in better clinical outcomes. ${ }^{8}$

The microorganisms predominantly found are Gram-negative aerobes like E. coli, Klebsiella, Proteus and Pseudomonas; Gram-positive cocci are also present like the Streptococci, Enterococci and Staphylococci. Anaerobes found in the bile are anaerobic streptococci, Clostridium welchii and Bacteroides fragilis. ${ }^{9}$

In Saudi Arabia, 25\% of patients undergoing cholecystectomy for gallstones were bacterial culture positive and the most common organisms isolated were E. coli (28.1\%), E. faecalis (15.6\%) and P. aeruginosa (9.4\%).10

The choice of antibiotics in patients with biliary sepsis will depend upon two important considerations- sensitivity and the concentration of antibiotics in bile. However, in patients undergoing elective surgery, the role of a prophylactic antibiotic is to achieve adequate serum levels above the minimal inhibitory concentration of the most likely suspected organism. Timing of antibiotic administration is crucial to prevent post-operative wound infections. Adequate tissue concentration of an antibiotic is necessary to achieve a maximal benefit. 11

In spite of modern standards of pre-operative preparation and operative techniques, post-operative wound infections occur in quite number of patients. In spite of using higher antibiotics, wounds which are expected to heal by first intention do not heal as desired.12

Several authors have found the definite correlation between the species of bacteria cultured from bile collected during surgery both from gall bladder and common bile duct and the species cultured from post-operative infections. Thus, it is important to take bile cultures routinely at the time of operation for antimicrobial prophylaxis to reduce the postoperative infection rate. The incidence, types of bacteria involved and their susceptibility to antibiotics need to be accurately predicted on the basis of results from recent bacteriological investigations of bile.

This study was undertaken to determine the microbiological profile and antibiotic sensitivity pattern of microorganism isolated from blood, bile and gallstones in patients with cholecystitis with or without cholelithiasis undergoing cholecystectomy to decide whether there is a need for change in the standard empirical antibiotic therapy administered. The aim of this study was:

1. To calculate the positivity of patients with bacteraemia in biliary tract infections.

2. To study the microbial profile by culture of bile samples.

3. To analyse and identify the aetiological microorganisms causing bacteraemia/septicaemia by conventional blood culture techniques.

4. To isolate and identify organism causing formation of gallstones.

5. Finally to determine antibiotic sensitivity pattern/antibiogram of the above isolates.

\section{MATERIALS AND METHODS}

The present study was undertaken to determine the microbial flora in the blood, bile and gallstones in patients with cholecystitis with or without cholelithiasis. Fifty patients were included in this study which was conducted in the Department of Microbiology, J.L.N. Medical College, Ajmer for a period of one year.

\section{Inclusion Criteria}

1. Patients admitted in various surgical units of J.L.N. Hospital, Ajmer diagnosed with cholecystitis with or without cholelithiasis undergoing cholecystectomy.

2. Demographic profile: All age group and both sexes will be included.

\section{Exclusion Criteria}

1. Patients who have been already administered antibiotics.

2. Cases of malignancy of gall bladder or biliary tract.

3. Patients of hepatic failure and in hepatic coma.

\section{Samples were processed as follows Blood Culture}

5-7 mL of blood in blood culture bottles containing brain heart infusion broth was taken using all aseptic precautions (Bedside inoculation).

\section{Bile Culture}

$3 \mathrm{~mL}$ of bile collected during operation was inoculated in blood culture bottles containing brain heart infusion broth using all aseptic precautions.

\section{Gallstone Culture}

After cholecystectomy, the gallbladder was cut open and a sample of stone was removed. After surface decontamination with ethanol the stone was broken down and material from the core of stone was taken and crushed pieces of gallstones were aseptically inoculated in brain heart infusion broth.

- In the lab, the culture bottles were kept in incubator at $37^{\circ} \mathrm{C}$ and were screened for any turbidity after $24 \mathrm{hrs}$. and after $48 \mathrm{hrs}$.

- In case the broth turned turbid, then subculturing was done on MacConkey agar and Blood agar which were then incubated at $37^{\circ} \mathrm{C}$ and then inspected for the type of growth.

- Colony characteristics of growth were noted.

- Then, Gram staining was done on the growth obtained on MacConkey or blood agar to identify the organisms.

- Then, biochemical tests were done from the growth to confirm identification of organisms.

- Hanging drop preparation for motility in Gram-negative bacteria for identification.

- Antibiotic susceptibility was done using the Kirby Bauer disc diffusion method using Muller Hinton agar for commonly used antibiotics depending on the growth i.e. Gram positive or Gram negative.

- Then, biochemical test result and Antibiotic sensitivity was recorded and analysed.

\section{Gram-negative Bacilli}

For Lactose fermenting and non-lactose fermenting colonies, further Gram staining for grouping, Hanging drop for Motility, 
Catalase and Oxidase tests were done. After which the following biochemical tests were done. They include:

- Indole test

- Methyl red test

- Simmon's Citrate test

- Christensen's Urease test

- Phenylalanine deaminase test

- Triple sugar iron test

- Glucose fermentation

- Lactose fermentation

- Sucrose fermentation.

These tests were done for Gram-negative bacteria.

\section{Gram-positive Cocci}

For Gram-positive cocci - Catalase test, oxidase tests were done. For cocci in clusters which are oxidase negative \& catalase positive--slide and tube coagulase, Mannitol fermentation tests were done.

For Gram-positive cocci in pairs and short chains which are catalase negative - Bacitracin sensitivity was done on BA.

\section{Antibiogram Testing}

The antibiogram testing was done as per CLSI guidelines using modified Kirby-Bauer method. If the organisms were not sensitive to any of the drugs, then a second line of antibiotics was put up using the same procedure as above.

\begin{tabular}{|c|c|c|}
\hline Sl.No. & First Line Drug & Second Line Drug \\
\hline 1 & Erythromycin (E) $15 \mu \mathrm{g}$ & $\begin{array}{c}\text { Amoxyclav (AMC) } \\
20+10 \mu \mathrm{g}\end{array}$ \\
\hline 2 & $\begin{array}{c}\text { Co-trimoxazole (COT) } \\
23.75+1.25 \mu \mathrm{g}\end{array}$ & \begin{tabular}{c} 
Linezolid (LZ) $30 \mu \mathrm{g}$ \\
\hline 3
\end{tabular} \\
$\begin{array}{c}\text { Gentamycin (GEN) } 10 \mu \mathrm{g} \\
\text { Vancomycin (V) } 30 \\
\mu \mathrm{g}\end{array}$ \\
\hline 5 & Ciprofloxacin (CIP) $5 \mu \mathrm{g}$ & \\
\hline \multicolumn{2}{|c|}{ Antibiotic Disc used for Gram-positive Organisms } \\
\hline
\end{tabular}

\begin{tabular}{|c|c|c|}
\hline Sl. No. & First Line Drug & Second Line Drug \\
\hline 1 & $\begin{array}{l}\text { Tetracycline } \\
\text { (TE) } 30 \mu \mathrm{g}\end{array}$ & $\begin{array}{l}\text { Amikacin } \\
(\mathrm{AK}) 30 \mu \mathrm{g}\end{array}$ \\
\hline 2 & $\begin{array}{l}\text { Ciprofloxacin } \\
\text { (CIP) } 5 \mu \mathrm{g}\end{array}$ & $\begin{array}{c}\text { Amoxyclav } \\
\text { (AMC) } 20+10 \mu \mathrm{g}\end{array}$ \\
\hline 3 & $\begin{array}{l}\text { Cefotaxime } \\
\text { (CTX) } 30 \mu \mathrm{g}\end{array}$ & $\begin{array}{l}\text { Ceftazidime } \\
\text { (CAZ) } 30 \mu \mathrm{g}\end{array}$ \\
\hline 4 & ----- & $\begin{array}{l}\text { Netilmicin } \\
\text { (NET) } 30 \mu \mathrm{g}\end{array}$ \\
\hline 5 & ------ & $\begin{array}{l}\text { Imipenem } \\
\text { (IMP) } 10 \mu \mathrm{g}\end{array}$ \\
\hline
\end{tabular}

\begin{tabular}{|c|c|c|}
\hline Sl. No. & First Line Drug & Second Line Drug \\
\hline 1 & $\begin{array}{l}\text { Tetracycline } \\
\text { (TE) } 30 \mu \mathrm{g}\end{array}$ & $\begin{array}{l}\text { Amikacin } \\
\text { (AK) } 30 \mu \mathrm{g}\end{array}$ \\
\hline 2 & $\begin{array}{l}\text { Ciprofloxacin } \\
\text { (CIP) } 5 \mu \mathrm{g}\end{array}$ & $\begin{array}{c}\text { Amoxyclav } \\
\text { (AMC) } 20+10 \mu \mathrm{g}\end{array}$ \\
\hline 3 & $\begin{array}{l}\text { Cefotaxime } \\
\text { (CTX) } 30 \mu \mathrm{g}\end{array}$ & $\begin{array}{l}\text { Ceftazidime } \\
\text { (CAZ) } 30 \mu \mathrm{g}\end{array}$ \\
\hline 4 & $\begin{array}{l}\text { Piperacillin } \\
\text { (PI) } 100 \mu \mathrm{g}\end{array}$ & $\begin{array}{l}\text { Imipenem } \\
\text { (IMP) } 10 \mu \mathrm{g}\end{array}$ \\
\hline \multicolumn{3}{|c|}{ Antibiotic Disc used for Pseudomonas Species } \\
\hline
\end{tabular}

Based on these tests, the following individual organisms were identified:
Staphylococcus aureus, Enterococcus faecalis, Klebsiella pneumoniae, Pseudomonas aeruginosa, Citrobacter freundii, Enterobacter aerogenes, Escherichia coli.

\section{RESULTS}

The present study was done to evaluate the antimicrobial profile and susceptibility pattern of the patients with cholecystitis with cholelithiasis undergoing cholecystectomy. Gallstones disease was more common in females as compared to males (F: M: 3.5: 1) and the maximum age incidence was in 41-50 years age group (38\%). This disease was more common in non- vegetarians as compared to the vegetarians $(52 \% \mathrm{v} / \mathrm{s}$ $48 \%$ ). Majority of patients were obese with $76 \%$ of patients having weight $>50 \mathrm{~kg}$.

Pain abdomen was the predominant symptom present in $88 \%$ of cases, flatulent dyspepsia in $44 \%$ cases and nausea/vomiting in $32 \%$ cases, while tenderness in right hypochondrium was present in $44 \%$ of cases. Out of total 50 cases, 18 i.e. $36 \%$ showed positive bile cultures and incidence of positive cultures increased with advancing age with maximum being positive in 41-60 years age group.

Gallstone culture was positive in 28 cases i.e. $56 \%$ of the total samples. Preoperative blood cultures of all patients were found sterile.

Most common organism isolated from bile was E. coli (44\% of positive cases) followed by Klebsiella (22\%) and Pseudomonas (16\%).

E. coli was again the most common organism isolated from gallstone culture ( $43 \%$ of positive cases) but Pseudomonas was more commonly isolated from gallstones than Klebsiella (29\% vs. $18 \%$ ).

Regarding the antibiotic susceptibility of bile and gallstones, the isolates were highly sensitive to $3^{\text {rd }}$ generation cephalosporins (ceftriaxone, ceftazidime) and aminoglycosides (amikacin).

Gram-negative isolates in bile were $100 \%$ sensitive to imipenem followed by $93 \%$ to Amikacin and Ceftazidime Clav (ceftazidime + clavulanic acid) and $85 \%$ to Amoxyclav (amoxicillin + clavulanic acid).

Staphylococcus was sensitive to Amoxyclav, Ciprofloxacin, Cotrimoxazole, Gentamicin, Linezolid, Tetracycline and Vancomycin but resistant to Ampicillin, Oxacillin and Erythromycin.

Enterococcus was sensitive to Amoxyclav, Ciprofloxacin, Linezolid, Tetracycline and Vancomycin but resistant to Ampicillin, Cotrimoxazole, Gentamicin and Erythromycin.

\begin{tabular}{|c|c|c|c|c|}
\hline $\begin{array}{c}\text { Age Group } \\
\text { (yrs.) }\end{array}$ & Female & Male & Total & Percentage \\
\hline $11-20$ & - & - & - & - \\
\hline $21-30$ & 5 & 2 & 7 & 14 \\
\hline $31-40$ & 11 & 5 & 16 & 32 \\
\hline $41-50$ & 16 & 3 & 19 & 38 \\
\hline $51-60$ & 3 & - & 3 & 6 \\
\hline $61-70$ & 2 & - & 2 & 4 \\
\hline $71-60$ & 2 & 1 & 3 & 6 \\
\hline Total & 39 & $\mathbf{1 1}$ & $\mathbf{5 0}$ & $\mathbf{1 0 0}$ \\
\hline \multicolumn{7}{|c|}{ Table 1. Age and Sex Distributions } \\
\hline
\end{tabular}




\begin{tabular}{|c|c|c|}
\hline Weight (Kg) & No. of Cases & Percentage \\
\hline $31-40$ & 2 & 4 \\
\hline $41-50$ & 10 & 20 \\
\hline $51-60$ & 23 & 46 \\
\hline$>60$ & 15 & 30 \\
\hline Total & $\mathbf{5 0}$ & $\mathbf{1 0 0}$ \\
\hline \multicolumn{2}{|c|}{ Table 2. Relationship with Weight } \\
\hline
\end{tabular}

\begin{tabular}{|c|c|c|c|}
\hline Sl. No. & Symptoms & $\begin{array}{c}\text { No. of } \\
\text { Cases }\end{array}$ & Percentage \\
\hline 1 & $\begin{array}{c}\text { Pain right } \\
\text { hypochondrium }\end{array}$ & 40 & 80 \\
\hline 2 & Diffuse pain abdomen & 4 & 8 \\
\hline 3 & Nausea/Vomiting & 16 & 32 \\
\hline 4 & Flatulent dyspepsia & 22 & 44 \\
\hline 5 & Fever & 6 & 12 \\
\hline 6 & $\begin{array}{c}\text { Tenderness in right } \\
\text { hypochondrium }\end{array}$ & 22 & 44 \\
\hline 7 & Palpable gallbladder & 4 & 8 \\
\hline \multicolumn{3}{|c|}{ Table 3. Sign and Symptoms } \\
\hline
\end{tabular}

\begin{tabular}{|c|c|c|}
\hline Bile Culture & No. of Cases & Percentage \\
\hline Positive & 18 & 36 \\
\hline Sterile & 32 & 64 \\
\hline Total & $\mathbf{5 0}$ & $\mathbf{1 0 0}$ \\
\hline \multicolumn{3}{|c|}{ Table 4. Bile Culture } \\
\hline
\end{tabular}

\begin{tabular}{|c|c|c|}
\hline Gallstone Culture & No. of Cases & Percentage \\
\hline Positive & 28 & 55 \\
\hline Sterile & 22 & 44 \\
\hline Total & $\mathbf{5 0}$ & $\mathbf{1 0 0}$ \\
\hline \multicolumn{2}{|c|}{ Table 5. Gallstone Culture } \\
\hline
\end{tabular}

\begin{tabular}{|c|c|c|}
\hline Organism & No. of Cases & Percentage \\
\hline E. coli & 8 & 44 \\
\hline Klebsiella & 4 & 22 \\
\hline Pseudomonas & 3 & 16 \\
\hline Enterobacter & 1 & 6 \\
\hline Enterococcus & 1 & 6 \\
\hline Staph. aureus & 1 & 6 \\
\hline \multicolumn{2}{|c|}{ Total } & $\mathbf{1 8}$ \\
\hline \multicolumn{2}{|c}{ Table 6. Organisms Isolated in Bile } \\
\hline
\end{tabular}

\begin{tabular}{|c|c|c|}
\hline Organism & No. of Cases & Percentage \\
\hline E. coli & 12 & 43 \\
\hline Klebsiella & 5 & 18 \\
\hline Pseudomonas & 8 & 29 \\
\hline Enterobacter & 2 & 7 \\
\hline Citrobacter & 1 & 3 \\
\hline Total & 28 & 100 \\
\hline \multicolumn{3}{|c|}{ Table 7. Organisms Isolated In Gallstones } \\
\hline
\end{tabular}

\begin{tabular}{|c|c|c|c|}
\hline Antibiotics & $\begin{array}{c}\text { Total } \\
\text { No. of } \\
\text { Gram -ve } \\
\text { Isolates }\end{array}$ & $\begin{array}{c}\text { No. of } \\
\text { Organism } \\
\text { Sensitive } \\
\text { Cases }\end{array}$ & Percentage \\
\hline Ampicillin & 13 & 3 & 23.07 \\
\hline Amoxyclav & 13 & 11 & 84.61 \\
\hline Amikacin & 13 & 12 & 92.3 \\
\hline Ceftriaxone & 13 & 9 & 69.23 \\
\hline Cefotaxime & 13 & 10 & 76.92 \\
\hline Ceftazidime & 13 & 10 & 76.92 \\
\hline Ceftazidime & 13 & 12 & 92.3 \\
\hline Clav & 13 & 9 & 69.23 \\
\hline Ciprofloxacin & 13 & 10 & 76.92 \\
\hline Gentamicin & 13 & 7 & 53.04 \\
\hline Tetracycline & 13 & 13 & 100 \\
\hline Imipenem & \multicolumn{3}{|c|}{} \\
\hline \multicolumn{2}{|c|}{ Table 8. Antibiotic Sensitivity of Bile Culture Isolates } \\
\hline
\end{tabular}

\begin{tabular}{|c|c|c|c|}
\hline Antibiotics & $\begin{array}{c}\text { Total } \\
\text { No. of } \\
\text { Gram -ve } \\
\text { Isolates }\end{array}$ & $\begin{array}{c}\text { No. of } \\
\text { Organism } \\
\text { Sensitive } \\
\text { Cases }\end{array}$ & Percentage \\
\hline Ampicillin & 19 & 2 & 10.52 \\
\hline Amoxyclav & 19 & 15 & 78.94 \\
\hline Amikacin & 19 & 17 & 89.47 \\
\hline Ceftriaxone & 19 & 16 & 84.21 \\
\hline Cefotaxime & 19 & 15 & 78.94 \\
\hline Ceftazidime & 19 & 15 & 78.94 \\
\hline Ceftazidime & 19 & 17 & 89.47 \\
\hline Clav & 19 & 12 & 63.15 \\
\hline Ciprofloxacin & 19 & 15 & 78.94 \\
\hline Gentamicin & 19 & 10 & 52.63 \\
\hline Tetracycline & 19 & 19 & 100 \\
\hline Imipenem & Table 9. Antibiotic Sensitivity of Gallstone Isolates \\
\hline \multicolumn{2}{|c|}{}
\end{tabular}

\section{DISCUSSION}

In our study, maximum number of patients were in 41-50 years age group (19 cases-38\%) and then in the 31-40 years age group (32\%) and Female: Male ratio was 3.5:1.

These results are in contrast to the study done by Mohan $\mathrm{H}$ et $\mathrm{al}^{2}$ in 2005 on 1100 cases in North India. They studied cases ranging from 10 years to 90 years and concluded that maximum number of patients were in the age group 31-40 years and the Female: Male ratio in their study was $6.4: 1$.

A similar study done by Chaudhry et al ${ }^{13}$ (1987) also reported maximum incidence in 31-40 years age group with a Female: Male ratio of 17:1. These results of this study are also in contrast with our study.

Our results are comparable with the study of Sutor D.J. et $\mathrm{al}^{14}$ (1973) who also reported the maximum incidence to be in the 41-50 years age group with a Female: Male ratio of 3:1.

Similarly, Vijaypal et al ${ }^{15}$ (1980) had also reported that maximum number of cases were in the $4^{\text {th }}$ and $5^{\text {th }}$ decade and that a Female: Male ratio in their study was $2.4: 1$ which is comparable with our results.

Our study showed a slightly higher incidence of cholelithiasis in non-vegetarians than in vegetarians $(54 \%$ of total cases vs. $46 \%$ of cases) which may be attributed to higher amount of saturated fatty acids in non-vegetarian diet. 
Tsai C. J. et al. (2004) ${ }^{16}$ were also of the same view and they in their studies concluded that higher consumption of saturated fatty acids is associated with increased risk of gallstone formation.

In our study, the maximum number of patients were in 51$60 \mathrm{~kg}$ weight group (46\%) while $30 \%$ had weight $>60 \mathrm{~kg}$.

These results are comparable with Whiting M.J. et al (1984) ${ }^{17}$ who also concluded that obese persons were at higher risk of cholelithiasis as they have increased biliary cholesterol levels.

Michael F. et al (1998) ${ }^{18}$ were also of the same opinion and they reported that reduced physical activity and increased obesity are independent risk factors for symptomatic gallstone disease.

The pathophysiological role of bacteria in the formation of gallstones was proposed long ago and using molecular genetic techniques, bacteria or their components can be demonstrated in most gallstones. Apart from molecular techniques, many studies have identified bacteria using the classical culture methods.

In our study, we cultured blood, bile and material from the centre of gallstones to identify presence of infection in these samples and its possible role in causing disease and its complication.

Long ago Harding A.J. ${ }^{19}$ in 1962 had shown the presence of microorganisms in culture of gallstones and similarly Large A. M. ${ }^{20}$ in 1963 had also concluded that infection of bile caused change in permeability of gall bladder mucosa leading to cholelithiasis.

In our study, bile cultures were positive in $36 \%$ of cases and our results are comparable with other studies.

Z. I. Malik ${ }^{21}$ in 2009 had reported a bile culture positive rate of $32 \%$ which is very similar to our study results, but $\mathrm{Al}$. Harbi et al ${ }^{10}$ (2001) had reported bile culture positivity of $25 \%$ which is lower than our results.

In our study, the highest incidence of bile infection was among 40-60 years age group ( 9 positive cases out of total 22 cases in that age group i.e. $41 \%$ ). These findings are similar to PRL Gomes series (2006) 22 where they concluded that incidence of infection was $39 \%$ in patients $>50$ years of age. In our study, the most common organism isolated in bile was E. coli ( $44 \%$ of positive cases) followed by Klebsiella (22\% of positive cases), Pseudomonas (16\%) and Enterobacter, Enterococcus and Staphylococcus each in $6 \%$ of positive cases. PRL Gomes et al. (2006) ${ }^{22}$ had also found out similar organisms in their series and percentage of E. coli and Klebsiella were almost similar to our series (i.e. $40 \%$ and $35 \%$ respectively) but they reported Enterobacter in 20\% and Pseudomonas in 5\% which is different from our results.

In another study, Z.I. Malik ${ }^{21}$ in 2009 had reported E. coli to be the commonest organism isolated in bile (44\%). In contrast to our study, they did not isolate Klebsiella in any of their samples while they isolated Proteus in $25 \%$ of their culture positive case which was not isolated in any sample of our series.

Salmonella typhi has long been recognised as an important organism which is cultured from bile and has been considered as an important organism responsible for gallstone disease, but in our study we did not isolate Salmonella typhi in any of the samples.

In other studies (PRL Gomes et al,23Abeysuriya et al,24 Z. I. Malik et $\mathrm{al}^{21}$ ), they also did not isolate Salmonella in any of their samples.

\begin{tabular}{|c|c|c|c|c|}
\hline Organism & $\begin{array}{c}\text { Our } \\
\text { Series }\end{array}$ & $\begin{array}{c}\text { PRL } \\
\text { Gomes } \\
\text { Series }\end{array}$ & $\begin{array}{c}\text { Z.I. } \\
\text { Malik } \\
\text { Series }\end{array}$ & $\begin{array}{c}\text { Abeysuriya } \\
\text { Series }\end{array}$ \\
\hline E. coli & $44 \%$ & $40 \%$ & $44 \%$ & $55.3 \%$ \\
\hline Klebsiella & $22 \%$ & $35 \%$ & --- & $5.3 \%$ \\
\hline Pseudomonas & $16 \%$ & $5 \%$ & $12.5 \%$ & $23.7 \%$ \\
\hline Enterobacter & $6 \%$ & $20 \%$ & --- & --- \\
\hline Enterococcus & $6 \%$ & --- & --- & $13.1 \%$ \\
\hline Staph. aureus & $6 \%$ & $5 \%$ & $5 \%$ & --- \\
\hline $\begin{array}{c}\text { Salmonella } \\
\text { typhi }\end{array}$ & ---- & --- & --- & --- \\
\hline $\begin{array}{c}\text { Comparison of Organisms Isolated in our Study with } \\
\text { Others }\end{array}$ \\
\hline \multicolumn{6}{|c|}{} \\
\hline
\end{tabular}

Our results are comparable with other series as far as the most common organism is considered i.e. E. coli, regarding other organisms the results are variable in different series, may be because of the different geographical locations of studies conducted.

In our study of the total 50 gallstones that were analysed by culture, 28 stones ( $56 \%$ ) had positive growth, 22 i.e. $44 \%$ were sterile.

Our study was similar to the study of H.S. Shukla et al ${ }^{25}$ in Banaras (2004) in that we could also isolate live bacteria from gallstone but our culture positive rates were low as compared to their study.

H.S. Shukla et al (2004) had reported that out of total 85 cases of cholelithiasis which they studied, 54 samples were positive, 12 were sterile and 19 samples were contaminated. While considering the organism isolated from gallstones the results of our study were different from H.S. Shukla series (2004)

We observed E. coli to be the commonest organism (12 cases out of 28 i.e. $43 \%$ ) while Shukla et al had observed Klebsiella spp. to be commonest isolate (17.5 of their cases) while in our series Klebsiella was seen in 5 samples i.e. $18 \%$ of the cases. H.S. Shukla et $\mathrm{al}^{25}$ reported E. coli in $15 \%$ of their cases. Our study showed Pseudomonas in $29 \%$ while it was 8.1\% in Shukla series. Enterobacter and Citrobacter in our series were $7 \%$ and $3 \%$ while they were $7.5 \%$ and $2.5 \%$ respectively in H.S. Shukla series.

Salmonella typhi long thought to be responsible for gallstone disease was not isolated in our series but H.S. Shukla et al had reported it in $1.5 \%$ cases. Thus, the organisms and their relative percentages were quite different in our series.

Thus, in our study, infection was present in $>50 \%$ of the cases either in bile or the stones or both; however, there was no isolate found in any of blood sample of patients because of chronic nature of infection after subsidence of acute illness. Hence, bacterial infection is an important contributory factor in pathogenesis of gallbladder disease.

Regarding the antibiotic susceptibility of the isolated organism from bile and gallstones our study concluded that among the 3rd generation cephalosporins, cefotaxime had low sensitivity, ceftriaxone had good sensitivity $(80-85 \%)$ while ceftazidime had the best sensitivity result (90\%). Among the aminoglycosides, amikacin had good sensitivity (varying up to $90 \%$ ) while gentamycin had a poor sensitivity pattern. 
Ampicillin had the lowest sensitivity rates (40\%), ciprofloxacin had good sensitivity results (80-85\%) while imipenem had $100 \%$ sensitivity rate.

Among the 3rd generation cephalosporins, our results are comparable with other series. Ceftriaxone had a good sensitivity pattern in our series as well as other series.
Cefotaxime showed low sensitivity pattern in our series while it had good sensitivity in PRL Gomes and Abeysuriya series. Amikacin and ciprofloxacin had high susceptibility rates in our series as well as in other series.

Gentamycin had low susceptibility rates in our series which is comparable with D. Valceanu series while the other 2 series had very good susceptibility rates for this antibiotic.

\begin{tabular}{|c|c|c|c|c|}
\hline Antibiotic & $\begin{array}{c}\text { Our series } \\
\text { Bile Stone }\end{array}$ & $\begin{array}{c}\text { PRL Gomes } \\
\text { Series Bile+gallstone }\end{array}$ & $\begin{array}{c}\text { D. Valceanu } \\
\text { Series (Bile) }\end{array}$ & $\begin{array}{c}\text { V.Abeysuriya } \\
\text { Series (Bile) }\end{array}$ \\
\hline Ceftriaxone & 8580 & 100 & 85 & 98 \\
\hline Cefotaxime & 7968 & 100 & -- & 100 \\
\hline Ceftazidime & 9593 & -- & 85 & 98 \\
\hline Amikacin & 8590 & 100 & -- & 100 \\
\hline Gentamycin & 7065 & 100 & 74 & 100 \\
\hline Ciprofloxacin & 8590 & 88 & -- & 100 \\
\hline Ampicillin & 4540 & 25 & 3.7 & 100 \\
\hline Imipenem & 100100 & 100 & -- & 100 \\
\hline \multicolumn{7}{r}{} \\
\hline
\end{tabular}

Thus, a 3rd generation cephalosporin with an aminoglycoside is a good empirical therapy to start with in cases of uncomplicated cholelithiasis and if patients are allergic to cephalosporin then ciprofloxacin may be used.

Our results thus comply with the previous studies regarding the presence of bacterial pathogen in the gall bladder of patients even while lacking any evidence of infection and inflammation, thus further enhancing their potent pathogenic implications and post-operative squeals that can occur following gallstones lost in peritoneal cavity during cholecystectomy.

\section{CONCLUSION}

Thus, we conclude that infection plays a key role in pathogenesis of chronic calculous cholecystitis and bile and gallstone culture is a good method to demonstrate the infective potential of bacteria colonising the gall bladder. Our study has shown bacteria in core of gallstones in $56 \%$ of cases, thus we recommend complete retrieval of all the stones and debris during cholecystectomy. Our study also recommends for an adequate antibiotic prophylaxis for cholecystectomy cases and a $3^{\text {rd }}$ generation cephalosporin combined with an aminoglycoside is a good empirical therapy to start with.

\section{ACKNOWLEDGMENT}

I want to thank late Dr. Blossom ma'am for her valuable guidance, advice and support in completing this research work successfully.

\section{REFERENCES}

1. Oddsdottir M, Hunter JG, Pham TH. Gall bladder and extra hepatic biliary system. In: Brunicardi FC, Anderson DK, Biliar TR, et al. eds. Schwartz principles of surgery. 9th edn. McGraw Hill Professional 2009:1135-67.

2. Mohan H, Puniya RPS, Dhawan SB, et al. Morphological spectrum of gallstone disease in 1100 cholecystectomies in North India. Indian J Surg 2005;67:140-2.
3. Unisa S, Jagannath P, Dhir V, et al. Population based study to estimate prevalence and determine risk factors of gallbladder diseases in the rural Gangetic basin of North India. HPB (Oxford) 2011;13(2):117-25.

4. Fukunaga FH. Gallbladdder bacteriology, histology and gallstones. Study of unselected cholecystectomy specimens in Honolulu. Arch Surg 1973;106(2):169-71.

5. Bornman PC, van Beljon JI, Krige JE. Management of cholangitis. J Hepatobiliary Pancreatic Surg 2003;10(6):406-14.

6. Claesson BE, Holmlund DE, Matzsch TW. Microflora of the gallbladder related to duration of acute cholecystitis. Surg Gynecol Obstet 1986;162(6):531-5.

7. Shimada K, Noro T, Inamatsu T, et al. Bacteriology of acute obstructive suppurative cholangitis of the aged. J Clin Microbiol 1981;14(5):522-6.

8. Kuo CH, Changchien CS, Chen JJ. et al. Septic acute cholangitis. Scand J Gastroenterol 1995;30(3):272-5.

9. Keighley MRB, Drysdale RB, Quoraishi AH, et al. Antibiotic treatment of biliary sepsis. Surgery Clinics of North America 1975;55(6):1379-90.

10. Al Harbi M, Osoba AO, Mowallad A, et al. Tract microflora in Saudi patients with cholelithiasis. Tropical Medicine International Health 2001;6(7):570-4.

11. Keighley MR, McLeish AR, Bishop HM, et al. Identification of the presence and type of biliary microflora by immediate gram stains. Surgery 1977;81(4):469-72.

12. Evans C, Pollock AV. The reduction of surgical wound infections by prophylactic parenteral cephaloridine. A controlled clinical trial. Br J Surg 1973;60(6):434-7.

13. Chaudhary NH, Chrungoo RK, Karihala PL, et al. Chronic cholecystitis. our experience. Current and Practice 1987;31:179.

14. Sutor DJ, Wooley SE. The nature and incidence of gallstones containing calcium. Gut 1973;14(3):215-20.

15. Vijaypal, Lakhtabia HS, Gehlot YVS, et al. A clinicopathological study of cholecystitis. Ind J Surg 1980;42:426. 
16. Tsai CJ, Leitzmann MF, Willett WC, et al. The effect of longterm intake of cis unsaturated fats on the risk for gallstone disease in men: a prospective cohort study. A prospective cohort study. Ann Intern Med 2004;141(7):514-22.

17. Whiting MJ, Hall JC, Iannos J, et al. The cholesterol saturation of bile and its reduction by chenodeoxycholic acid in massively obese patients. International J of Obesity 1984;8(6):681-8.

18. Leitzmann MF, Giovannucci EL, Rimm EB, et al. The relation of physical activity to risk for symptomatic gallstone disease in men. Ann Intern Med 1998;128(6):417-25.

19. Rains HAJ. Researches concerning the formation of gallstones. Brit Med J 1962;2(5306):685-91.

20. Small DM. Cholesterol nucleation and growth in gallstone formation. N Engl J Med 1980;302(23):1305-7.
21. Malik ZI, Malik MAN, Salahuddin 0, et al. Micro flora of bile aspirates in symptomatic cholelithiasis. JRMC 2009;13(1):38-40.

22. Maki T. Pathogenesis of calcium bilirubinate gallstone: role of E. coli, $\beta$-glucuronidase and coagulation by inorganic ions, polyelectrolytes and agitation. Ann Surg 1966;164(1):90-100.

23. PRL Gomes, SSN Fernando, DD Weerasekara, et al. Aerobic bacteria associated with symptomatic gallstone disease and their antimicrobial susceptibility. Galle Medical Journal 2006;11(1):9-12.

24. Abeysuriya V, Deen KI, Wijesuriya T, et al. Microbiology of gallbladder bile in uncomplicated symptomatic cholelithiasis. Hepatobiliary Pancreat Dis Int 2008;7(6): 633-7.

25. Hazrah P, Oahn KTH, Tewari M, et al. The frequency of live bacteria in gallstone. Hepato Pancreato Biliary Journal 2004;6(1):28-32. 